\title{
Initiation of Trastuzumab by Women Younger Than 64 Years for Adjuvant Treatment of Stage I-III Breast Cancer
}

\author{
Huei-Ting Tsai, PhDa; Claudine Isaacs, MDa; Filipa C. Lynce, MDa; Suzanne C. O’Neill, PhDa; \\ Chunfu Liu, ScD ${ }^{\text {b }}$ Marc D. Schwartz, PhDa; Nandini Selvam, PhD ; Yingjun Zhou, MS ${ }^{\mathrm{a}}$; \\ and Arnold L. Potosky, $\mathrm{PhD}^{\mathrm{a}}$
}

\begin{abstract}
Purpose: Studies have reported disparities by age and race in the initiation of adjuvant trastuzumab for the initial treatment of older women with early-stage breast cancer, but less is known about its initiation in younger patients. Therefore, we assessed temporal trends and clinical and demographic factors associated with trastuzumab initiation in a large, population-based cohort of patients aged $<64$ years in 5 states. Methods: Using a cancer registry and claims-linked data set of 13,398 women with incident invasive breast cancer from 2006 to 2011, we identified 934 patients aged <64 years with HER2-positive stage I-III breast cancer. We assessed trastuzumab initiation within the first 9 months after diagnosis and conducted logistic regression analyses to assess sociodemographic and clinical factors associated with trastuzumab initiation. Results: From 2006 to 2011, trastuzumab initiation steadily increased in patients with node-positive (from 65\% to $91 \%$ ) and node-negative (from $39 \%$ to $75 \%$ ) breast cancers. Several tumor-related factors were associated with trastuzumab initiation, including high histologic grades (adjusted odds ratio [aOR], 6.43; 95\% Cl, 3.27-12.65; and aOR, 3.25; 95\% Cl, 1.66-6.36, for grades 3 and 2 , respectively), node-positive status (aOR, 1.88; 95\% Cl, 1.28-2.78; $P=.001)$, tumor size $>2 \mathrm{~cm}(\mathrm{aOR}, 1.50 ; 95 \% \mathrm{Cl}, 1.04-2.16 ; P=.03)$, and hormone receptor-negative status $(\mathrm{aOR}, 1.51 ; 95 \% \mathrm{Cl}, 1.01-2.26 ; P=.04)$. We found a null effect of race. Conclusions: Adjuvant trastuzumab therapy for early-stage breast cancer has been widely disseminated among women aged $<64$ years. The initiation of this targeted therapy was associated with higher-risk features, consistent with practice guidelines.
\end{abstract}

J Natl Compr Canc Netw 2017;15(5):601-607

\section{Background}

The administration of trastuzumab, a humanized monoclonal antibody targeting HER2 on the surface of cancer cells, significantly improves survival among patients with HER2-positive breast cancer. Based on results from a joint analysis of 2 large randomized trials showing a $52 \%$ and $33 \%$ reduction in recurrence and mortality, respectively, trastuzumab was FDA-approved in

\footnotetext{
From a Georgetown Lombardi Comprehensive Cancer Center, Washington, DC, and ${ }^{\mathrm{b}} \mathrm{HealthCore,} \mathrm{Inc.,} \mathrm{Alexandria,} \mathrm{Virginia.}$

Submitted October 14, 2016; accepted for publication January 9, 2017.

Dr. Isaacs has received honoraria from Genentech/Roche, Celgene, AstraZeneca, and Pfizer; served in a consulting or advisory role for Pfizer, Caris Life Sciences, and Genentech/Roche; served on speakers' bureaus for Genentech, Celgene, Pfizer, and AstraZeneca; received research funding from Novartis, Pfizer, Genentech, and Tesaro; and has accepted travel, accommodations, and expenses provided by Caris Life Sciences. Drs. Liu and Selvam are employees of HealthCore, Inc., a wholly owned subsidiary of Anthem, Inc. The remaining authors have disclosed that they have no financial interests, arrangements, affiliations, or commercial interests
}

November 2006 as adjuvant treatment for patients with early-stage, HER2-positive, node-positive breast cancer in combination with cytotoxic chemotherapies. ${ }^{1}$ In January 2008, trastuzumab was approved for use as singleagent therapy after standard adjuvant chemotherapy for early-stage, HER2-positive breast cancer, independent of nodal status, based on data from the Herceptin Adjuvant (HERA) trial demonstrating a $46 \%$ reduction in

with the manufacturers of any products discussed in this article or their competitors.

Author contributions: Study conception and design: Tsai, Isaacs, Lynce, O'Neill, Liu, Schwartz, Potosky. Acquisition of data: Potosky, Tsai, Lynce, Selvam. Analysis and interpretation of data: Tsai, Isaacs, Lynce, O'Neill, Liu, Schwartz, Potosky. Drafting of the manuscript: Tsai. Critical revision of the manuscript for important intellectual content: All authors. Statistical analysis: Tsai, Zhou. Obtaining funding: Potosky, Tsai, O'Neill, Schwartz. Correspondence: Huei-Ting Tsai, PhD, Georgetown Lombardi Comprehensive Cancer Center, 3300 Whitehaven Street, NW, Suite 4100, Room 4137, Washington, DC 20007.

E-mail: Hueiting.Tsai@georgetown.edu 
recurrence. ${ }^{2}$ Since 2006, NCCN has recommended trastuzumab for patients with HER2-positive and node-positive breast cancer, or for those with a tumor $>1 \mathrm{~cm}$ and node-negative disease. ${ }^{3}$ In 2010, the NCCN Clinical Practice Guidelines in Oncology (NCCN Guidelines) expanded the recommendation for considering trastuzumab to women with nodenegative breast cancer whose tumors measured 0.6 to $1 \mathrm{~cm}$ with grade 2 or 3 disease. $^{4}$ These expanded recommendations demonstrate the increased role trastuzumab plays in the care of women with stage I-III HER2-positive breast cancer.

Although professional guidelines have recommended trastuzumab for stage I-III breast cancer since 2005, data on its use in clinical practice are very limited. This is especially true for women aged $<65$ years due to lack of sufficiently comprehensive, linked data sources that include this population. Of the 231,840 women diagnosed with invasive breast cancer each year, $>133,000$ are aged $<65$ years., ${ }^{5,6}$ Compared with older patients, these younger patients have a higher percentage of HER2-positive cancers (20\% vs $13 \%$ for age $<65$ years and $>65$ years, respectively $)^{7}$ and often have more aggressive tumors that require adjuvant chemotherapy. ${ }^{8,9}$ Thus, it is particularly important to assess the dissemination of trastuzumab treatment in this young population. We evaluated temporal trends and clinical and sociodemographic factors associated with trastuzumab initiation among women with breast cancer aged $<64$ years.

\section{Methods}

\section{Data Sources}

We linked data between cancer registries from 5 states (California, Georgia, Kentucky, New York, and Ohio) and administrative claims consisting of medical and pharmacy records for members enrolled in Anthem-affiliated plans maintained by HealthCore (Wilmington, DE), an independently operated, wholly owned subsidiary of Anthem. Anthem is an independent licensee of Blue Cross Blue Shield Association and serves members in 14 states. We obtained HER2 status from the cancer registry data. Each cancer registry started collecting HER2 statuses in 2005 for California, 2008 for Kentucky, and 2009 for New York, Ohio, and Georgia. More details of the data linkage can be found in previous publications. ${ }^{10}$

\section{Study Population}

We first identified incident invasive breast cancer diagnosed from January 1, 2006, through December 31, $2011(\mathrm{~N}=13,398)$ and followed through April 30, 2012 (Figure 1). We then excluded patients diagnosed with stage IV breast cancer or missing stage information $(n=843)$, and those with negative $(n=5,072)$, borderline $(n=142)$, or unknown $(n=6,258)$ HER2 status, which was mostly due to lack of registry reporting of HER2 status in earlier years. We also excluded women who did not have any medical coverage during the first 9 months after diagnosis $(n=111)$. We excluded 38 more women who were aged 64 years at the time of diagnosis because HealthCore claims data do not include complete information on drug use when women become eligible for Medicare at age 65 years. The final study population included 934 women aged $<64$ years when diagnosed with AJCC-defined stage I-III HER2-positive breast cancer. ${ }^{11}$ A total of $778(83.3 \%)$ of the women had continuous coverage during the first 9 months after diagnosis; most of the 156 women without continuous coverage had $\geq 6$ months of coverage after their breast cancer diagnosis.

\section{Measures}

The outcome of the study was receipt of trastuzumab as adjuvant therapy for stage I-III HER2-positive breast cancer, defined as initiation of trastuzumab within the first 9 months after diagnosis. We chose this 9-month cutoff to balance the time patients may need to complete surgery and/or adjuvant chemotherapy before initiating trastuzumab, and to avoid

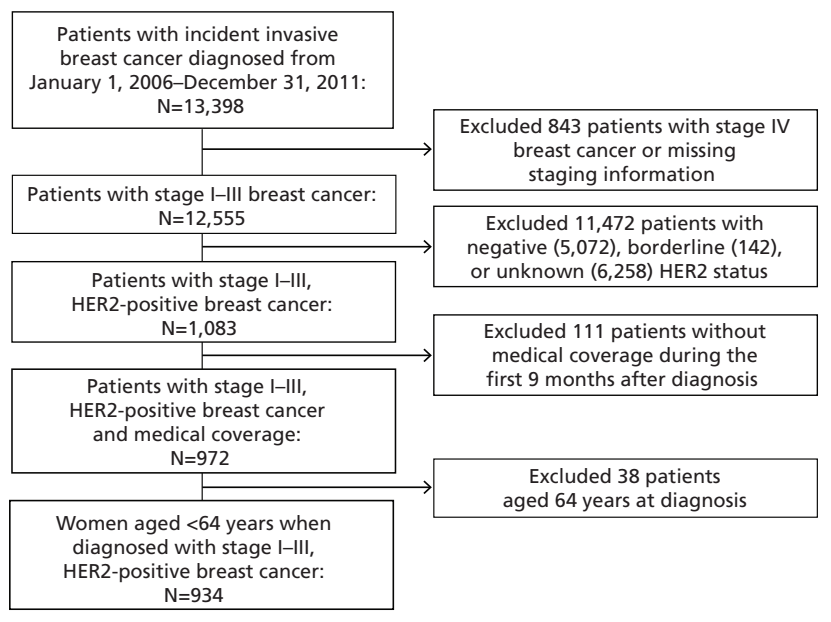

Figure 1. Flow diagram of study patient selection. 
including patients who may have experienced disease progression and are receiving trastuzumab for metastatic disease. From registry data, we obtained patients' sociodemographic factors (age at diagnosis, race/ethnicity, marital status, and state of residence) and cancer-related characteristics, including nodal status; AJCC stage; estrogen receptor (ER), progesterone receptor (PR), and HER2 status; tumor size; histologic grade; and history of cancer before breast cancer diagnosis. Information on TNM staging was obtained from registry data using the AJCC Breast Cancer Staging (version 6 or 7, depending on year of diagnosis). ${ }^{11}$ Based on NCCN Guidelines and tumor size information available in our dataset, we defined women as high risk (for recurrence) if they had either positive lymph nodes or a tumor $>2 \mathrm{~cm}$ (T2-T4). ${ }^{3,4}$ Because of lack of specific tumor size information in our data, we were unable to determine which patients had node-negative disease and tumors 1 to $2 \mathrm{~cm}$ and would also have been eligible for trastuzumab. From the claims data maintained by HealthCore, we obtained patients' median household income and percentage of college education completion derived from census tract data based on their residential address. Using longitudinal medical records available in the claims data, we assessed the presence of 30 comorbidities included in the Elixhauser comorbidity index score ${ }^{12}$ the year before breast cancer diagnosis. We grouped those 30 comorbidities into cardiovascular (congestive heart failure, hypertension, peripheral vascular disorders, and diabetes) or other comorbidities.

\section{Statistical Analysis}

We first described the characteristics of patients with HER2-positive breast cancer and their use of trastuzumab in the total population. We then conducted a logistic regression with trastuzumab use as the dependent variable to identify patient demographic and clinical characteristics associated with trastuzumab use in the total population. Variable selection was based on expert opinions and consideration of the model fitting process. For example, we adjusted for regional (state-level) differences in practice patterns and first year of HER2 status reporting. We combined prior cardiovascular history with other comorbidities due to small sample size in separate categories and very similar estimates with trastuzumab use. Third, we calculated predicted probability of new trastuzumab users within the first 9 months of their breast cancer diagnosis by calendar year to examine the temporal trend of trastuzumab initiation by nodal status and clinical indication. We also conducted a sensitivity analysis among women who had continuous coverage in the first 9 months after breast cancer diagnosis.

\section{Results}

\section{Population Characteristics and Their Trastuzumab Use}

This study included a total of 934 patients with stage I-III HER2-positive breast cancer diagnosed from 2006 to 2011. Overall, 680 (73\%) of the participants initiated trastuzumab within 9 months of diagnosis. Among trastuzumab users, the median time to trastuzumab initiation was 70 days from diagnosis. Among 680 trastuzumab users, 448 had continuous medical coverage for at least 1 year and $84 \%$ of these completed a 1 -year course of trastuzumab as recommended.

Table 1 describes the demographic and clinical characteristics of our study cohort. Most patients were aged 40 to 59 years (72\%) and were non-Hispanic white $(76 \%)$. Most women had tumors that were $\leq 2 \mathrm{~cm}(53 \%)$, node-negative $(61 \%)$, either ERand/or PR-positive (68\%), and of poorly or undifferentiated histologic grade (56\%).

\section{Temporal Trends of Trastuzumab Use}

There was a steadily increasing trend in trastuzumab initiation among patients with stage I-III HER2positive breast cancer diagnosed between 2006 and 2011. Increased trastuzumab initiation was evident in patients with node-positive breast cancer (from $65 \%$ to $91 \%$ ) and those with node-negative breast cancer (from 39\% to 75\%; Figure 2). Although trastuzumab initiation increased over time among women with a greater risk of recurrence, there was also an increased initiation in patients with nodenegative tumors $\leq 2 \mathrm{~cm}$ (from $39 \%$ to $74 \%$; Figure $3)$. We further examined histologic grade among women with node-negative tumors $\leq 2 \mathrm{~cm}$ and found that $95 \%$ of those using trastuzumab had tumors that were grade 2 or 3 (data not shown). The temporal effect of increased trastuzumab initiation remained after we adjusted for other patient characteristics (adjusted odds ratio [aOR], 2.04; 95\% CI, 1.323.16 for a 2008-2009 diagnosis, and 4.03; 95\% CI, 
Tsai et al

\begin{tabular}{|c|c|c|}
\hline Population Characteristics & $\begin{array}{l}\text { Total } \\
\text { N (\%) }\end{array}$ & $\begin{array}{c}\text { Trastuzumab Use } \\
\text { N (\%) }\end{array}$ \\
\hline Total & $934(100)$ & $680(73)$ \\
\hline \multicolumn{3}{|l|}{ Sociodemographic characteristics } \\
\hline \multicolumn{3}{|l|}{ Year of diagnosis } \\
\hline $2006-2007$ & $246(26)$ & $141(57)$ \\
\hline 2008-2009 & $261(28)$ & $196(75)$ \\
\hline 2010-2011 & $427(46)$ & $343(80)$ \\
\hline \multicolumn{3}{|l|}{ Age at diagnosis, y } \\
\hline 24-39 & $106(11)$ & $82(77)$ \\
\hline $40-49$ & $300(32)$ & $225(75)$ \\
\hline $50-59$ & $370(40)$ & $266(72)$ \\
\hline $60-63$ & $158(17)$ & $107(68)$ \\
\hline \multicolumn{3}{|l|}{ Race/Ethnicity } \\
\hline Non-Hispanic white & $713(76)$ & $515(72)$ \\
\hline Non-Hispanic black & $47(5)$ & $34(72)$ \\
\hline Hispanic & $61(7)$ & $45(74)$ \\
\hline Asian and Pacific Islanders & $100(11)$ & $75(75)$ \\
\hline All others & $13(1)$ & $11(85)$ \\
\hline \multicolumn{3}{|l|}{ Marital status } \\
\hline Married & $665(71)$ & $482(73)$ \\
\hline Not married & $258(28)$ & $190(74)$ \\
\hline Missing & $11(1)$ & $8(73)$ \\
\hline \multicolumn{3}{|l|}{ State of residence } \\
\hline California & $623(67)$ & $437(70)$ \\
\hline Georgia & $75(8)$ & $60(80)$ \\
\hline Kentucky & $66(7)$ & $49(74)$ \\
\hline New York & $82(9)$ & $63(77)$ \\
\hline Ohio & $88(9)$ & $71(81)$ \\
\hline \multicolumn{3}{|l|}{ Area } \\
\hline Rural & $37(4)$ & $25(68)$ \\
\hline Urban & $884(95)$ & $645(73)$ \\
\hline Missing & $13(1)$ & $10(77)$ \\
\hline \multicolumn{3}{|c|}{ Median household income (quintiles) } \\
\hline Q1 & $140(15)$ & $104(74)$ \\
\hline Q2 & $176(19)$ & $121(69)$ \\
\hline Q3 & $185(20)$ & $139(75)$ \\
\hline Q4 & $204(22)$ & $151(74)$ \\
\hline Q5 & $216(23)$ & $155(72)$ \\
\hline Missing & $13(1)$ & $10(77)$ \\
\hline
\end{tabular}

ata on median household income and percent completing college education are derived from census tract data.

(continued)
${ }^{a}$ Data on median household income and percent completing college education are derived from census tract data.

receipt, including high histologic grade (aOR, 6.43; 95\% CI, 3.27-12.65 for grade 3, and aOR, 3.25; 95\% CI, 1.66-6.36 for grade 2, vs grade $1 ; \mathrm{P}<.001$ ), node-positive status (aOR, 1.88; 95\% CI, 1.28-2.78; $P=.001$ ), both ER- and PR-negative status (aOR, 1.51; 95\% CI, 1.01-2.26; $P=.04)$, and tumor size

\begin{tabular}{|c|c|c|}
\hline Population Characteristics & $\begin{array}{l}\text { Total } \\
\text { N (\%) }\end{array}$ & $\begin{array}{c}\text { Trastuzumab Use } \\
\text { N (\%) }\end{array}$ \\
\hline \multicolumn{3}{|l|}{ Completed college $\mathrm{a}^{\mathrm{a}}$} \\
\hline$<20 \%$ & $169(18)$ & $127(75)$ \\
\hline $20 \%$ to $<30 \%$ & 406 (44) & $289(71)$ \\
\hline $30 \%$ to $<40 \%$ & $227(24)$ & $166(73)$ \\
\hline$\geq 40 \%$ & $119(13)$ & $88(74)$ \\
\hline Unknown/Missing & $13(1)$ & $10(77)$ \\
\hline \multicolumn{3}{|l|}{ Clinical characteristics } \\
\hline \multicolumn{3}{|l|}{ Tumor size } \\
\hline 0 & $3(0)$ & $3(100)$ \\
\hline$\leq 2 \mathrm{~cm}(\mathrm{~T} 1)$ & $497(53)$ & $325(65)$ \\
\hline$>2 \mathrm{~cm}(\mathrm{~T} 2-\mathrm{T} 4)$ & $432(46)$ & $350(81)$ \\
\hline Missing & $2(0)$ & $2(100)$ \\
\hline \multicolumn{3}{|l|}{ Stage at diagnosis } \\
\hline Stage I & $388(42)$ & $238(61)$ \\
\hline Stage II & $378(41)$ & $300(79)$ \\
\hline Stage III & $168(18)$ & $142(85)$ \\
\hline \multicolumn{3}{|l|}{ Lymph node status } \\
\hline Positive & 366 (39) & $302(83)$ \\
\hline Negative & $568(61)$ & $378(67)$ \\
\hline \multicolumn{3}{|c|}{ Estrogen or progesterone receptor status } \\
\hline$\geq 1$ positive & $633(68)$ & $439(69)$ \\
\hline Both negative & $297(32)$ & $239(81)$ \\
\hline Both missing or 1 negative & $4(0)$ & $2(50)$ \\
\hline \multicolumn{3}{|l|}{ Histologic grade } \\
\hline 1: Well differentiated & $55(6)$ & $20(36)$ \\
\hline 2: Moderately differentiated & $304(33)$ & $200(66)$ \\
\hline 3: Poorly or not differentiated & $522(56)$ & $424(81)$ \\
\hline Missing & $53(6)$ & $36(68)$ \\
\hline \multicolumn{3}{|l|}{ History of prior cancer } \\
\hline No & $900(96)$ & $656(73)$ \\
\hline Yes & $34(4)$ & $24(71)$ \\
\hline \multicolumn{3}{|l|}{ Cardiovascular comorbidity } \\
\hline No & $892(96)$ & $649(73)$ \\
\hline Yes & $42(5)$ & $31(74)$ \\
\hline \multicolumn{3}{|l|}{ Other comorbidity } \\
\hline No & $852(91)$ & $620(73)$ \\
\hline Yes & $82(9)$ & $60(73)$ \\
\hline
\end{tabular}

\section{Patient Characteristics Associated With Trastuzumab Use}

Aside from year of diagnosis, several clinical factors were significantly associated with trastuzumab
2.45-6.63 for a 2010-2011 diagnosis, compared with 2006-2007 diagnosis; $P<.001$; Table 2). 
Trastuzumab Initiation in Women Younger Than 64 Years

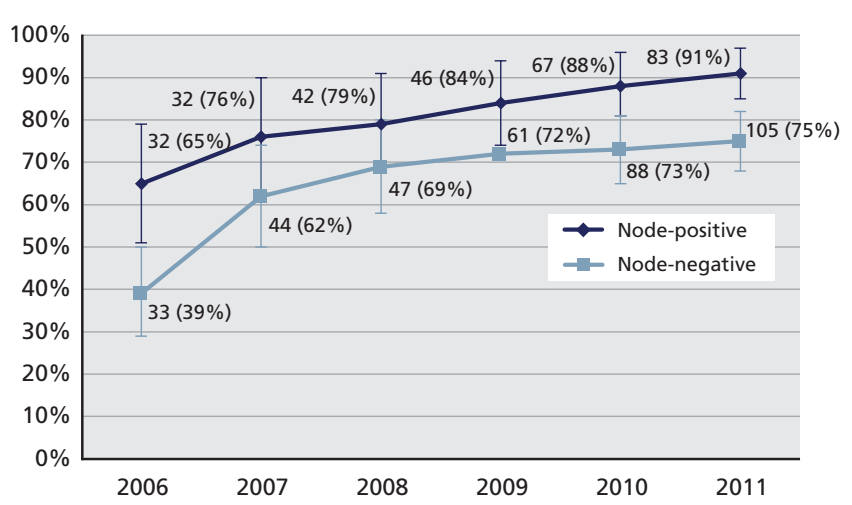

Figure 2. Temporal trend of trastuzumab use (percentage and $95 \%$ $\mathrm{Cl}$ ) by nodal status for women aged $<64$ years with HER2-positive, stage I-III breast cancer.

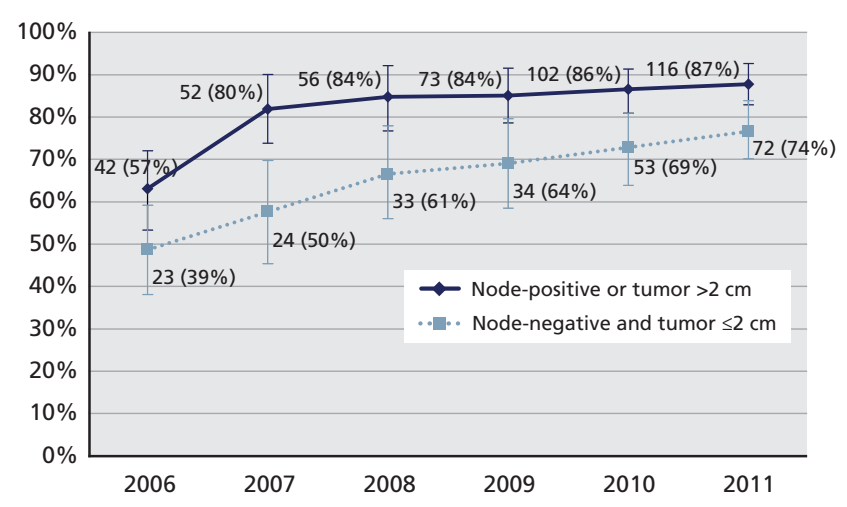

Figure 3. Temporal trends of trastuzumab use (percentage and $95 \%$ $\mathrm{Cl}$ ) among patients with HER2-positive, stage I-III breast cancer by (1) node-positive or tumor $>2 \mathrm{~cm}$ and (2) node-negative and tumor $\leq 2 \mathrm{~cm}$.
$>2 \mathrm{~cm}(\mathrm{aOR}, 1.50 ; 95 \% \mathrm{CI}, 1.04-2.16 ; \mathrm{P}=.03$; Table 2). Notably, trastuzumab initiation did not differ by race in this population $(72 \%$ in white, $72 \%$ in black, $74 \%$ in Hispanic, $75 \%$ in Asian; aOR, 1.03; 95\% CI, 0.68-1.56; $P=.88$ for nonwhite vs white population; Tables 1 and 2). In our sensitivity analysis among women with continuous 9 month coverage, we found the same predictors associated with trastuzumab use (see supplemental eTable 1, available with this article at JNCCN.org).

\section{Discussion}

Before the era of trastuzumab and other HER2-targeted therapies, HER2-positive breast cancers were associated with poor outcomes. ${ }^{13,14}$ Despite strong evidence showing the benefit of adjuvant trastuzum$\mathrm{ab}$ initiation for women with HER2-positive breast cancer, no studies exist on its initiation in younger women, a patient subgroup with a higher percentage of HER2-positive cancer. In this study, we assessed trastuzumab initiation in a large and diverse population-based cohort treated in general clinical practice. We found that trastuzumab was well disseminated in young women with breast cancer, particularly among those with node-positive tumors. We also observed a large temporal increase in trastuzumab initiation among patients with node-negative tumors $<2 \mathrm{~cm}$, reflecting the evolution of clinical guidelines in expanding the indications for adjuvant trastuzumab over the past decade. We did not find racial differences in trastuzumab initiation in this young population as reported in prior studies of patients aged $\geq 65$ years. The strongest clinical factors associated with trastuzumab initiation were those that would be predicted based on practice guidelines during our study period and include node-positive status, high histologic grade, hormone receptor-negative disease, or larger tumors. Thus, our study effectively demonstrates the dissemination of adjuvant trastuzumab for HER2-positive stage I-III breast cancer among patients at the highest risk of breast cancer recurrence and mortality.

Two prior studies using the SEER-Medicare linked database demonstrated significant age and racial disparities in trastuzumab initiation among women aged $\geq 65$ years with early-stage HER2-positive breast cancer in 2010 to 2011. . $^{15}, 16$ One study reported that $50 \%$ of 1,162 white and $40 \%$ of 104 black women aged $\geq 65$ years with HER2-positive early-stage breast cancer received adjuvant trastuzumab. Additionally, they found that black women were $25 \%$ less likely to start trastuzumab than white women even after adjusting for other sociodemographic and cancer-related characteristics. In another study of 770 women aged $\geq 66$ years without a history of congestive heart failure, $56 \%$ of eligible women received trastuzumab, but non-Hispanic black women were 3 -fold more likely to not receive trastuzumab than non-Hispanic white women $(\mathrm{aOR}, 3.14 ; 95 \% \mathrm{CI}$, 1.38-7.17). In contrast to these 2 prior studies, our study population, all diagnosed at $\leq 64$ years of age, was more likely to have aggressive disease features. Freedman et $\mathrm{al}^{17}$ assessed receipt of trastuzumab by race/ethnicity among 1,190 women, $74 \%$ of whom were $<60$ years of age, receiving care from 8 medical centers. They found no significant differences by race/ethnicity in trastuzumab initiation. The lack of racial disparities in trastuzumab initiation in our 
Tsai et al

\begin{tabular}{|c|c|c|c|}
\hline $\begin{array}{l}\text { Population } \\
\text { Characteristics }\end{array}$ & $\begin{array}{l}\text { Total } \\
\text { N (\%) }\end{array}$ & $P$ Value & $\begin{array}{l}\text { Overall } \\
P \text { Value }\end{array}$ \\
\hline \multicolumn{4}{|c|}{ Sociodemographic characteristics } \\
\hline \multicolumn{4}{|l|}{ Year of diagnosis } \\
\hline 2006-2007 & 1.0 (Ref) & & \\
\hline 2008-2009 & $2.04(1.32-3.16)$ & .001 & $<.001$ \\
\hline $2010-2011$ & $4.03(2.45-6.63)$ & $<.001$ & \\
\hline \multicolumn{4}{|l|}{ Age at diagnosis, y } \\
\hline $24-39$ & $1.41(0.72-2.78)$ & .32 & .61 \\
\hline $40-49$ & $1.33(0.80-2.19)$ & .27 & \\
\hline $50-59$ & $1.10(0.69-1.76)$ & .70 & \\
\hline $60-63$ & 1.0 (Ref) & & \\
\hline \multicolumn{4}{|l|}{ Race/Ethnicity } \\
\hline White & 1.0 (Ref) & & \\
\hline Nonwhite & $1.03(0.68-1.56)$ & .88 & .88 \\
\hline \multicolumn{4}{|l|}{ Marital status } \\
\hline Married & 1.0 (Ref) & & \\
\hline Not married & $1.05(0.72-1.54)$ & .80 & .80 \\
\hline \multicolumn{4}{|l|}{ State of residence } \\
\hline California & 1.0 (Ref) & & \\
\hline Georgia & $0.94(0.44-2.02)$ & .87 & .63 \\
\hline Kentucky & $0.71(0.35-1.45)$ & .35 & \\
\hline New York & $0.62(0.31-1.21)$ & .16 & \\
\hline Ohio & $0.92(0.45-1.79)$ & .83 & \\
\hline \multicolumn{4}{|l|}{ Completed college ${ }^{a}$} \\
\hline$<20 \%$ & 1.0 (Ref) & & \\
\hline $20 \%$ to $<30 \%$ & $0.82(0.50-1.35)$ & .44 & .85 \\
\hline $30 \%$ to $<40 \%$ & $0.84(0.48-1.45)$ & .53 & \\
\hline$\geq 40 \%$ & $0.95(0.51-1.79)$ & .89 & \\
\hline \multicolumn{4}{|l|}{ Clinical characteristics } \\
\hline \multicolumn{4}{|l|}{ Tumor size } \\
\hline$\leq 2 \mathrm{~cm}(\mathrm{~T} 1)$ & 1.0 (Ref) & & \\
\hline$>2 \mathrm{~cm}$ (T2-T4) & $1.50(1.04-2.16)$ & .03 & .03 \\
\hline \multicolumn{4}{|l|}{ Lymph node status } \\
\hline Positive & 1.0 (Ref) & & \\
\hline Negative & $1.88(1.28-2.78)$ & .001 & .001 \\
\hline \multicolumn{4}{|c|}{ Estrogen or progesterone receptor status } \\
\hline$\geq 1$ positive & 1.0 (Ref) & & \\
\hline Both negative & $1.51(1.01-2.26)$ & .04 & .04 \\
\hline \multicolumn{4}{|l|}{ Histologic grade } \\
\hline 1: Well differentiated & 1.0 (Ref) & & \\
\hline $\begin{array}{l}\text { 2: Moderately } \\
\text { differentiated }\end{array}$ & $3.25(1.66-6.36)$ & $<.001$ & $<.001$ \\
\hline $\begin{array}{l}\text { 3: Poorly or not } \\
\text { differentiated }\end{array}$ & $6.43(3.27-12.65)$ & $<.001$ & \\
\hline \multicolumn{4}{|c|}{ Comorbidity within 1 year before breast cancer diagnosis } \\
\hline No & 1.0 (Ref) & & \\
\hline Yes & $1.12(0.65-1.94)$ & .69 & .69 \\
\hline
\end{tabular}

a Data on median household income and percent completing college education are derived from census tract data. study may be partially due to some clinical factors in women aged $<64$ years that lead patients and providers to consider trastuzumab necessary, such as longer life expectancy and increased presence of higher-risk features for cancer recurrence. It is also possible that our small sample size of nonwhite women limited our power to detect any differences.

The temporal trends we observed are likely due to evolving evidence and practice guidelines that called for treating more subsets of women with stage I-III breast cancer, such as women with node-negative disease with tumors $>1 \mathrm{~cm}$ beginning in 2006, and women with tumor size $\leq 1 \mathrm{~cm}$ but with high histologic grade (2 or 3 ) in 2010. Among 336 patients in our study with node-negative, grade 2 or 3 tumors that were $\leq 2 \mathrm{~cm}$ in size, trastuzumab initiation steadily increased from $49 \%$ in 2006 to $78 \%$ in 2011. This increase reflects practitioners' adherence to clinical recommendations for trastuzumab initiation in this young population.

Dissemination of adjuvant trastuzumab was not perfect or universal. Our cohort consisted of $19 \%$ of women with higher-risk features who did not receive adjuvant trastuzumab. This may be partly due to age effects; our data showed that women aged 60 to 63 years accounted for $21 \%$ and $12 \%$ of the total cohort in the nontrastuzumab and trastuzumab groups, respectively. We investigated the possibility that comorbidity might help explain this result, because some studies have reported an association between trastuzumab initiation and an increased risk of heart failure. ${ }^{18}$ However, we did not observe that cardiovascular comorbidity was associated with decreased trastuzumab initiation among the $19 \%$ of patients with high-risk features of recurrence. This finding may also be partly due to the low prevalence $(5 \%)$ of cardiovascular comorbidity in our study population.

This study is important in that it is among the first to report use patterns of trastuzumab initiation among patients $<64$ years diagnosed with stage IIII breast cancer. The study findings were limited to patients with commercial insurance. Because trastuzumab costs approximately $\$ 70,000$ USD for 1 year of treatment, ${ }^{19,20}$ out-of-pocket costs for women without any insurance pose serious financial barriers to its initiation. Subsequent studies comparing initiation of this targeted therapy in women with commercial versus public coverage would be desirable. Additionally, due to lack of exact tumor size data, we were 
unable to distinguish patients recommended for trastuzumab initiation (tumor size $>1 \mathrm{~cm}$, or tumors $0.6-1$ $\mathrm{cm}$ graded as 2 or 3 ) from all patients with tumor size $\leq 2 \mathrm{~cm}$. Therefore, we used conservative criteria and only counted patients diagnosed with tumors $>2 \mathrm{~cm}$ as having high-risk features because these patients clearly met clinical recommendations for trastuzumab initiation. The time trend analyses are limited by the distinct time contribution and small sample size in most registries, except California. Because of the lack of data, this study is unable to assess the effect of different drivers on the initiation of trastuzumab, such as insurance type and patient and physician preferences.

\section{Conclusions}

Trastuzumab treatment is well disseminated among patients $<64$ years of age with stage I-III HER2positive breast cancer. Our data did not find racial disparities in trastuzumab initiation, as reported in prior studies of women aged $\geq 65$ years. This study found overall excellent adherence to professional recommendations regarding adjuvant trastuzumab initiation in clinical practice for women diagnosed at $<64$ years of age at high risk of recurrence after initial treatment for stages I-III, HER2-positive breast cancer.

\section{References}

1. Romond EH, Perez EA, Bryant J, et al. Trastuzumab plus adjuvant chemotherapy for operable HER2-positive breast cancer. N Engl J Med 2005;353:1673-1684.

2. Piccart-Gebhart MJ, Procter M, Leyland-Jones B, et al. Trastuzumab after adjuvant chemotherapy in HER2-positive breast cancer. N Engl J Med 2005;353:1659-1672.

3. Carlson RW, Anderson BO, Bensinger W, et al. NCCN Clinical Practice Guidelines in Oncology: Breast Cancer. Version 1.2005. Accessed January 12, 2015. To view the most recent version of these guidelines, visit NCCN.org.

4. Carlson RW, Allred DC Anderson BO, et al. NCCN Clinical Practice Guidelines in Oncology: Breast Cancer. Version 1.2010. Accessed January 12, 2015. To view the most recent version of these guidelines, visit NCCN.org.

5. National Cancer Institute. Table 1.22 U.S. Complete Prevalence Counts, Invasive Cancers Only, January 1, 2009. Available at: https://seer.cancer. gov/archive/csr/1975_2009_pops09/results_single/sect_01_table.22_2pgs. pdf. Accessed August 18, 2016.

6. American Cancer Society. Breast Cancer Facts \& Figures 2013-2014. Available at: http://www.cancer.org/acs/groups/content/@research/ documents/document/acspc-042725.pdf. Accessed September 22, 2016.

7. Clarke CA, Keegan TH, Yang J, et al. Age-specific incidence of breast cancer subtypes: understanding the black-white crossover. J Natl Cancer Inst 2012;104:1094-1101.

8. Azim HA Jr, Partridge AH. Biology of breast cancer in young women. Breast Cancer Res 2014;16:427.

9. Pollan M. Epidemiology of breast cancer in young women. Breast Cancer Res Treat 2010;123(Suppl 1):3-6.

10. O'Neill SC, Isaacs $\mathrm{C}$, Chao $\mathrm{C}$, et al. Adoption of gene expression profiling for breast cancer in us oncology practice for women younger than 65 years. J Natl Compr Canc Netw 2015;13:1216-1224.

11. Edge S, Byrd DR, Compton CC, et al, eds. AJCC Cancer Staging Manual, 7th ed. New York, NY: Springer; 2010.

12. Elixhauser A, Steiner C, Harris DR, Coffey RM. Comorbidity measures for use with administrative data. Med Care 1998;36:8-27.

13. Gonzalez-Angulo AM, Litton JK, Broglio KR, et al. High risk of recurrence for patients with breast cancer who have human epidermal growth factor receptor 2-positive, node-negative tumors $1 \mathrm{~cm}$ or smaller. J Clin Oncol 2009;27:5700-5706.

14. Slamon DJ, Clark GM, Wong SG, et al. Human breast cancer: correlation of relapse and survival with amplification of the HER-2/neu oncogene. Science 1987;235:177-182.

15. Vaz-Luis I, Lin NU, Keating NL, et al. Treatment of early-stage human epidermal growth factor 2-positive cancers among medicare enrollees: age and race strongly associated with non-use of trastuzumab. Breast Cancer Res Treat 2016;159:151-162.

16. Reeder-Hayes K, Peacock HS, Meng K, et al. Disparities in use of human epidermal growth hormone receptor 2-targeted therapy for early-stage breast cancer. J Clin Oncol 2016;34:2003-2009.

17. Freedman RA, Hughes ME, Ottesen RA, et al. Use of adjuvant trastuzumab in women with human epidermal growth factor receptor 2 (HER2). positive breast cancer by race/ethnicity and education within the National Comprehensive Cancer Network. Cancer 2013;119:839-846.

18. Tsai HT, Isaacs C, Fu AZ, et al. Risk of cardiovascular adverse events from trastuzumab (Herceptin) in elderly persons with breast cancer: a population-based study. Breast Cancer Res Treat 2014;144:163-170.

19. Kurian AW, Thompson RN, Gaw AF, et al. A cost-effectiveness analysis of adjuvant trastuzumab regimens in early HER2/neu-positive breast cancer. J Clin Oncol 2007;25:634-641.

20. Leung W, Kvizhinadze G, Nair N, Blakely T. Adjuvant trastuzumab in HER2-positive early breast cancer by age and hormone receptor status: a cost-utility analysis. PLoS Med 2016;13:e1002067.

See JNCCN.org for supplemental online content. 